\title{
RÉGIMEN JURÍDICO DEL USO DE LA MARCA EN LA PUBLICIDAD
}

\author{
Nuria Martínez Sánchez \\ Doctoranda del Programa de Doctorado en Ciencias Económicas, \\ Empresariales y Jurídicas. UAL \\ Email: nuria_ms_@hotmail.com
}

RESUMEN: La marca es un signo distintivo esencial en cualquier empresa. Mientras que la publicidad se convierte en la pieza angular en la comercialización del producto marcado. La confabulación de ambos elementos posibilita la captación de los potenciales consumidores. Debido a su enjundia, es preciso establecer una serie de límites a esta conexión marca-publicidad, lo cual se hace a través de una regulación eficaz, coherente y ponderada, tanto a nivel nacional como internacional, que garantice un uso adecuado de la publicidad de la marca en el mercado.

PALABRAS CLAVE: publicidad, marca, consumidores, fraude, legalidad.

ABSTRACT: Brand is a distinctive sign that is essential in any business. While the publicity becomes angular piece in the marked product marketing. The conspiracy of both elements enables the recruitment of potential consumers. Because of its substance, it necessary to set some limits to this connection of branding and advertising, which are done through a regulation effective, coherent and weighted, both nationally and internationally, ensuring proper use of advertising for the brand in the market.

KEYWORDS: advertising, brand, consumers, fraud, legality. 


\section{Introducción: consumidor, marca y publicidad.}

Alude el profesor ANTONIO CARO ${ }^{1}$ a la estrecha relación existente entre marca y publicidad, la cual se ha ido consolidando a lo largo del siglo XX y lo que resta del XXI, formando de tal manera un "matrimonio bien avenido cuyos miembros forman un conjunto indisociable en el que resulta incluso difícil discernir dónde empieza el uno y dónde acaba el otro”. Y nosotros podríamos añadir, que de esa unión, nacen los potenciales consumidores, los hijos de ese matrimonio.

Para ejemplificar esta relación, podemos referenciar al prestigioso publicista LUIS BASSAT ${ }^{2}$, el cual nos señala un dato clarificador de la magnitud que puede alcanzar una marca, muchas veces, gracias a su publicidad. Esa magnitud se mide por los consumidores fieles al citado signo distintivo. Dice BASSAT “ ¿Sabía que la palabra más conocida en la lengua inglesa, después de "O.K.", es "Coca-Cola”? Sin duda, este dato nos puede servir como barómetro para medir el valor real de las marcas en nuestra sociedad". Cierto es que si vamos a casi cualquier parte del mundo, a un lugar del cual desconocemos su idioma, entramos en un bar, y decimos "coca-cola", casi seguro que nos ponen una. ¿Por qué? Ello se debe claramente a su alto grado de difusión y notoriedad. Coca-Cola es una marca, nació, creció y se reprodució hasta límites al principios inimaginables. En parte, en gran parte podríamos decir, esa propagación y difusión es consecuencia del impacto de la publicidad, la relación marca-publicidad ha sido fundamental en este proceso. No podemos olvidar que la famosa y a la vez desconocida fórmula de la Coca-Cola tiene que ver en este éxito, debido a que por su sabor y elaboración goza de muchos adeptos, pero, seguramente el mayor mérito de conseguir alzarse en el top de productos vendidos y consumidos habitualmente, lo tiene sus sucesivas campañas publicitarias, por lo menos a la hora de dar a conocer la marca, una vez que se prueba el producto, éste es el que fideliza consumidores. Suele decirse que, detrás de una gran marca, hay un buen producto. $\mathrm{Y}$ el hecho de que una gran marca tenga fieles seguidores, que siguen comprándola, eligiéndola frente a nuevos productos similares,

\footnotetext{
1 CARO, A., "Marca y publicidad: un matrimonio por amor”, en Trípodos, número 18, Barcelona, 2006, pp. 9-21. 2 BASSAT, L., El libro rojo de las marcas: cómo construir marcas con éxito, Ediciones España Calpe, S.A., 2006, p. 30.
} 
nos hace pensar que es verdad. Sin embargo, cuando tienen frente a ustedes dos o más productos, de ninguno de los cuales es consumidor habitual, ¿qué marca la diferencia entre comprar uno y comprar otro? Muchas veces, es la publicidad la que decanta la balanza hacia un lado o hacia otro. Esto es solo un ejemplo de los frutos que puede aportar la estrecha relación existente entre marca-publicidad-consumidor. Una buena conjunción de estos elementos puede ser traducida en éxito tanto para el empresario como para la agencia de publicidad como para los consumidores que se ven satisfechos con el producto.

Es cierto que hay algunas marcas, probablemente las menos, que no destinan ni tiempo ni dinero a la publicidad. El caso más conocido, traído a colación por el profesor ANTONIO CARO ${ }^{3}$, es el de ZARA, marca de ropa española más conocida del grupo Inditex, la cual no utiliza los usuales medios masivos de comunicación sino que debe su difusión al no menos importante "boca a boca" entre consumidores, además de la ubicación privilegiada de sus tiendas en el centro neurálgico de las ciudades. Esta marca tiene gran relevancia en el panorama textil a nivel mundial, contando con tiendas en las ciudades más importantes del planeta. Ello a pesar de su no inversión en publicidad en medios de comunicación de gran difusión. Pero como decíamos estos casos son los menos, la mayoría de empresas publicitan sus anuncios a través de televisión, prensa, radio, Internet...

La marca, o más bien la empresa propietaria de la misma, quiere volar, quiere conocer mundo, tiene afán de relacionarse con la gente, quiere hacer amigos. Y así, como amigos podríamos denominar a los consumidores habituales de un producto enmascarado en una determinada marca, fieles seguidores que la acompañarán durante toda su vida. $\mathrm{O}$ acaso no hemos escuchado alguna vez, una pregunta del tipo ¿tú que eres más de Cola Cao o de Nesquik? ¿de Coca Cola o de Pepsi? Y la respuesta no suele ser "de ambas", sino de una u otra marca, porque el consumidor tiende a fidelizarse a una marca. Mas, mucha culpa de la elección de una u otra, es la

\footnotetext{
3 CARO, A., "Marca y publicidad..." op cit.
} 
forma de difusión de la citada marca, es decir, la publicidad que se realice de la misma.

Una vez que el consumidor prueba el producto puede hacerse adepto al mismo, pero para ello es necesaria esa prueba, lo que podríamos llamar "morder el anzuelo". Siendo ese anzuelo la propia publicidad que se hace del citado producto y, sosteniendo la caña, el empresario que quiere pescar el pez más grande, ese potencial consumidor que podría ser un fiel cliente.

Parece clara la estrecha relación existente entre esta familia a priori bien avenida, pero ello implica tener claros tanto los derechos que ostentan cada una de las partes comprometidas en la citada relación como los límites que encuadran a cada miembro de este clan.

\section{El uso de la marca en la publicidad: el uso de la marca propia y el uso} de la marca ajena.

Las marcas nacen en el seno de una empresa, para ser usadas por su propietario o propietarios en el mercado, con la función de identificar el producto marcado y diferenciarlo del resto. Pero en muchas ocasiones, no sólo utilizan las marcas los titulares registrales de las mismas, sino también otros empresarios ajenos a la compañía. De hecho, apunta el abogado EDUARDO ARSENIO ORÉ SOSA4, que muchos propietarios de marcas renombradas, de gran prestigio, obtienen la mayoría de sus ingresos gracias a los contratos de licencia y de merchandising.

Así pues, encontramos dos tipos de usos de la marca. El uso de la marca propia, que realiza el titular de dicha marca para identificar su producto del resto y, el uso de la marca ajena. Este último tipo lo debemos subdividir en tres variantes. En primer lugar, encontramos el uso consentido de la marca ajena, el cual tiene lugar

4 ORÉ SOSA, E.A., "Usos permitidos de la marca ajena”, en Estudio Oré Guardia (abogados), disponible en www.oreguardia.com.pe 
cuando media un contrato de licencia o merchandising entre el titular de la marca y un tercero, o cuando se cede voluntariamente ese derecho de uso. En segundo lugar, hacemos referencia a los supuestos en los que no existe consentimiento ni autorización del titular de la marca para su utilización por un ente ajeno a la empresa, pero, sin embargo, legalmente este último puede hacer uso de la misma, respetando, como veremos, unos límites encuadrados en el marco jurídico correspondiente. Estos últimos son denominados usos permitidos o lícitos de la marca ajena. Y, en tercer lugar, encontramos los usos ilícitos de la marca ajena, los cuales se identificar con un uso no permitido ni por el titular de la marca ni amparado por la legislación vigente. Ante esta vulneración de los derechos del titular de la marca, ¿qué medidas puede llevar a cabo el mismo frente al uso no autorizado de su marca por terceros?

La propia Oficina Española de Patentes y Marcas $^{5}$ nos da la respuesta a esta cuestión. Ante todo es preciso resaltar la competencia del titular de la marca registrada para hacer valer sus derechos frente a la vulneración de los mismos por terceros. Una vez captada la infracción, es aconsejable que se ponga en contacto con un abogado especializado en la materia, que le asesore sobre las pautas que se han de seguir, como por ejemplo, el envío de una carta al presunto infractor (denominada "intimación a cesar en la práctica"). Hay muchas formas de vulnerar los derechos del titular de una marca, una de ellas, que actualmente se da con gran frecuencia, es la imitación de productos por empresarios chinos, los cuales falsifican a grandes marcas. Una vez que las autoridades tienen conocimiento de este hecho proceden al registro de las naves industriales donde suelen encontrarse las citadas falsificaciones e incautan el contenido de las mismas. En la página web de la OEPM encontramos una sección dedicada a la usurpación de derechos de propiedad industrial con amplia información sobre el tema, que es de gran ayuda en estos supuestos.

Pero como decíamos anteriormente existen muchos modos de vulnerar los derechos del propietario de una marca, y otra de las formas es a través de la

\footnotetext{
${ }^{5}$ El secreto está en la Marca. Introducción a las marcas dirigida a las pequeñas y medianas empresas, Guía sobre la Propiedad Industrial y las Pymes, disponible en http://www.oepm.es
} 
publicidad. En este punto es necesario traer a colación la denominada autorregulación o autodisciplina publicitaria, la cual puede definirse en palabras de la profesora FERNANDO MAGARZO 6 como un sistema voluntariamente establecido por las empresas que integran el sector publicitario (anunciantes, agencias y medios de comunicación) a través del cual se procura que el ejercicio de la actividad publicitaria se haga de forma legal, honesta y responsable, en beneficio de los consumidores, de los competidores, del mercado publicitario y de la sociedad en general. De manera que quienes se adhieren a un mecanismo de autodisciplina publicitaria se someten de forma voluntaria a unas determinadas normas de conducta, cuyo cumplimiento es vigilado por un órgano independiente de control.

En este sentido, la autorregulación publicitaria supone un compromiso con la sociedad por parte de la industria de este sector, frente a su grandes garantes: la libertad de expresión y libertad de empresa, muchas veces restringidas por el marco jurídico vigente por la necesidad de proteger a ciertos sectores sociales como los menores o determinados bienes jurídicos como la salud pública.

\section{Tipos de publicidad que aprovechan la reputación ajena.}

\subsection{La publicidad adhesiva o parasitaria.}

La denominada publicidad adhesiva o parasitaria 7 se considera un tipo de publicidad desleal, porque a través de ella el empresario pretende aprovechar indebidamente la reputación ajena en su propio beneficio. Aludiendo a DE MIGUEL 8 , cabe decir que en este tipo de publicidad, el anunciante intenta equiparar sus productos con los ajenos, utilizando, a estos fines, expresiones como "tan bueno como...", "la misma calidad que...", “del tipo de...”, "según el sistema de...”, etc.

\footnotetext{
6 FERNANDO MARGAZO, M.R., "La consolidación de la autorregulación publicitaria en España: fomento normativo y reconocimiento jurisprudencial", en Estudios sobre Consumo, número 84, 2008, pp. 71-83.

${ }^{7}$ TATO PLAZA, A. "Derecho de la marca..." op cit.

${ }^{8}$ DE MIGUEL ASENSIO, P.A., "Prácticas desleales y comunicaciones comerciales", en Estudios y comentarios legislativos, Cívitas, enero 2015.
} 
Dicho en palabras de la profesora BARONA VILAR" "la publicidad adhesiva es aquella en la que el anunciante trata de beneficiarse de las ventajas del goodwill y de la reputación mercantil o profesional adquirida por una marca competidora; se trata, en suma, de un aprovechamiento de la reputación ajena del que se obtiene un beneficio".

Dice el profesor LEMA DEVESA 10 que la publicidad adhesiva, en la que el anunciante equipara los productos o servicios propios a los de un competidor, lucrándose de la reputación ajena en su propio beneficio tiene lugar, cuando el empresario utilice tablas de equivalencia, indicando al consumidor que el producto anunciado, generalmente desconocido, se corresponde con una marca renombrada. Añade que también se produce publicidad adhesiva cuando se menciona la marca ajena de manera injustificada.

Esta modalidad tiene su fundamento jurídico en el artículo 12 de la Ley de Competencia Desleal ${ }^{11}$, que bajo la rúbrica "Explotación de la reputación ajena" recoge un supuesto perfectamente aplicable a este tipo de aprovechamiento. Así pues, dice el precepto "Se considera desleal el aprovechamiento indebido, en beneficio propio o ajeno, de las ventajas de la reputación industrial, comercial o profesional adquirida por otro en el mercado. En particular, se reputa desleal el empleo de signos distintivos ajenos o de denominaciones de origen falsas acompañados de la indicación acerca de la verdadera procedencia del producto o de expresiones tales como "modelos", "sistema”, “tipo", "clase” y similares".

Sin embargo, la doctrina mayoritaria es partidaria de anclar la publicidad adhesiva en un doble marco jurídico. Por un lado, se regula, en el mencionado derecho de la competencia desleal y, por otro, confluyendo con éste, en el derecho marcario. La relación entre estos dos ámbitos normativos ha experimentado una

\footnotetext{
${ }^{9}$ BARONA VILAR, S., Tutela civil y penal de la publicidad, Tirant lo Blanch y Universitat de València, Valencia, 1999, p.105.

${ }^{10}$ LEMA DEVESA, C., "La publicidad comparativa en la Unión Europea”, en Nueva Época, número 16, 2014.

${ }^{11}$ Ley 3/1991, de 10 de enero, de Competencia Desleal. "BOE" núm. 10, de 11 de enero de 1991 (BOE-A-1991-628).
} 
evolución considerable a lo largo del tiempo, demostrando una influencia recíproca en ambas disciplinas.

Así, respecto de la publicidad adhesiva, confusionista, comparativa desleal debemos fijarnos en factores que habitualmente se nos muestran, tales como la forma de configurar el mensaje, el contexto, el contenido de la página con la que enlaza, así como las características de los productos o servicios promocionados; pues son estos los elementos utilizados para conseguir que el destinatario o consumidor active el enlace correspondiente y la configuración del mensaje no dé lugar a situaciones de publicidad desleal en atención a la información sobre la página web o los productos o servicios que se incluye en el mensaje, siendo fundamental que se configure y se ponga a disposición de los destinatarios de manera que no pueda inducir a error, ni generar engaño o confusión 12 , marco en el que resulta relevante la prohibición de las prácticas señuelo y prácticas promocionales engañosas establecidas en el artículo 22 LCD.

Como ejemplo de esa relación podemos aludir a la incorporación a la Ley 17/2001, de 7 de diciembre, de Marcas ${ }^{13}$, cuya definición jurídica de las marcas y los nombres comerciales notorios y renombrados se regula en el art. $8^{14}$.

Pues bien, el régimen contenido en la Ley de Marcas 15 que afecta a la publicidad adhesiva, es el referente a la protección de los signos distintivos que

\footnotetext{
12 Acerca de estos riesgos en relación con las prácticas publicitarias en Internet, vid. FTC, "Dot Com Disclosures: How to Make Effective Disclosures in Digital Advertising”, marzo 2013, http://www.ftc.gov.

13 Ley 17/2001, de 7 de diciembre, de Marcas. "BOE” núm. 294, de 8 de diciembre de 2001 (BOE-A-2001-23093).

14 Llegados a este punto es preciso hacer referencia a la novedad introducida en la Ley 17/2001 de Marcas, que contiene por primera vez en nuestro ordenamiento jurídico una definición legal del concepto de marca notoria y marca renombrada, fijando el alcance de su protección. Así pues, dispone la LM en su artículo 8.1 que, "No podrá registrarse como marca un signo que se a idéntico o semejante a una marca o nombre comercial anteriores aunque se solicite su registro para productos o servicios que no sean similares a los protegidos por dichos signos anteriores cuando, por ser éstos notorios o renombrados en España, el uso de esa marca pueda indicar una conexión entre los productos o servicios amparados por la misma y el titular de aquellos signos o, en general, cuando ese uso, realizado sin justa causa, pueda implicar un aprovechamiento indebido o un menoscabo del carácter distintivo o de la notoriedad o renombre de dichos signos anteriores". La Ley de Marcas define en su artículo cuarto, apartado primero, a la marca como "todo signo susceptible de representación gráfica que sirva para distinguir en el mercado los productos o servicios de una empresa de los de otras". Y lo mismo hace con el nombre comercial en su artículo 87.1, al definirlo como "todo signo susceptible de representación gráfica que identifica a una empresa en el tráfico mercantil y que sirve para distinguirla de las demás empresas que desarrollan actividades idénticas o similares". Salvo disposición contra, lo dispuesto en relación a la Ley de Marcas será de aplicación al nombre comercial, en la medida que no sea incompatible con su propia naturaleza.

${ }^{15}$ La normativa sobre competencia desleal desempeña una importante función complementaria de la legislación de marcas en relación con la tutela de los signos distintivos en el mercado, operando ante la inexistencia de derechos de exclusiva o más allá de sus límites y su contenido, tal y como se aprecia en la STS (Sala de lo Civil, Secc. $1^{\text {a }}$ ) núm.
} 
proporciona la citada legislación y que se garantiza a través de la concesión de dos derechos de propiedad industrial: el derecho de propiedad sobre la marca y el derecho de propiedad sobre el nombre comercial ${ }^{16}$.

De tal forma, que de esa confluencia de ambas disciplinas jurídicas nace la regulación de la explotación de la marca y/o nombre comercial ajeno. Y bajo su amparo, la protección que confiere el Registro de Marcas al titular de la marca registrada se define por el derecho exclusivo de utilización de la misma en el tráfico económico, así como la facultad de prohibir su uso a terceros sin su consentimiento (art. 34.1 y 2 LM $)^{17}$.

Por su parte, hemos de tratar sobre la distinción entre las marcas y nombres comerciales notorios y renombrados, la cual reside en el grado de difusión entre el público. Así, las marcas y nombres comerciales notorios serán aquellos que puedan considerarse ampliamente conocidos en el sector del mercado al que pertenecen. Por su parte, las marcas o nombres comerciales renombrados son aquellos conocidos por el público en general.

La Ley de Marcas extiende las prohibiciones de uso de la marca registrada sin consentimiento del titular a la marca no registrada "notoriamente conocida" en

\footnotetext{
95/2014, de 11 de marzo (RJ 2014, 2245). Buena parte de los actos de competencia desleal y de las prácticas comerciales con los consumidores o usuarios tipificados en los Capítulos II y III LCD comprenden situaciones en las que se utilizan en el mercado signos o elementos identificativos sobre los que terceros tienen ciertos derechos sin su consentimiento. Tal puede ser el caso, en particular, de los actos de engaño, que incluyen las conductas que contengan información falsa o que pueda inducir a error relativa, por ejemplo, a la identidad del empresario ( art. 5 LCD), así como las omisiones engañosas (art. 7 LCD), que recoge la SAP de Jaén (Secc. 1ª) núm. 166/2013, de 13 noviembre, referida a una web donde relativa al ofrecimiento de servicios; los actos de confusión, apreciados en la SAP de Madrid (Sección 28 ${ }^{\mathrm{a}}$ ) no 131/2009 de 18 mayo (AC 2009, 1907) Fdto. Dcho. $4^{\circ}$, en relación con un supuesto de utilización de páginas web en las que se vendían los productos plagiando la apariencia, contenidos y nombre de dominio de un competidor., en los que puede ser determinante el «riesgo de asociación por parte de los consumidores respecto de la procedencia de la prestación» (art. 6 LCD); los actos de denigración (art. 9 LCD), fundamentados en la STS (Sala Civil, Secc. $1^{\text {a }}$ ) núm. 236/2014, de 7 de mayo, Fdto. Dcho. $3^{\circ}$.; y otros como los actos de comparación, que implican la alusión a un competidor (art. 10 LCD); los actos de imitación de prestaciones de terceros (art. 11 LCD); la explotación de la reputación ajena, que comprende el empleo de signos distintivos ajenos acompañados de expresiones como "tipo", "clase" y similares (art. 12 LCD); las prácticas engañosas por confusión para los consumidores (art. 20 LCD); y las prácticas engañosas por confusión (art. 25 LCD).

${ }^{16}$ VILAJOANA ALEJANDRE, S., Las leyes de la publicidad: límites jurídicos de la actividad publicitaria, UOC, 2011, p.93.

17 STJUE (Sala 1 $\left.{ }^{\text {a }}\right)$, de 8 julio 2010 (TJCE 2010\223).
} 
España pero, en este último caso, la protección se limita a los productos o servicios similares a aquellos para los que utiliza la marca o el nombre comercial notorio o renombrado (art. 34.5).

Ante la doble protección (derecho marcario y derecho de competencia desleal) antes mencionada, la doctrina entiende que a los supuestos de utilización de la marca ajena en publicidad se les deberá aplicar, en primera instancia, el contenido de la normativa de marcas; únicamente cuando se den circunstancias adicionales que así lo exijan, se les aplicará, también, la LCD y, en contadas ocasiones, se podrá aplicar solamente la LCD (por ejemplo, en caso de no estar la marca ajena registrada), como indica la profesora VILAJOANA ALEJANDRE ${ }^{18}$.

Por tanto, con relación a la publicidad adhesiva y en amparo a lo recogido en los preceptos anteriores, un tercero ajeno a la marca no podrá usar ésta en el tráfico económico para su beneficio sin el consentimiento de su titular o sin justa causa, salvo que el uso que le confiera esté exento de prohibición alguna. Y el titular de la misma cuenta con una doble vía de protección para velar por sus derechos.

\subsection{La publicidad comparativa.}

Otra modalidad de publicidad que puede llegar a ser considerada como comportamiento desleal, es la publicidad comparativa. Y decimos puede llegar a ser y no que lo es porque no toda publicidad comparativa puede ser calificada de desleal, solamente aquella que no respete determinados requisitos lo será.

Este tipo de publicidad, junto con la publicidad engañosa despertó cierta preocupación en cuanto a su regulación en Europa, pues existían grandes diferencias

\footnotetext{
${ }^{18}$ VILAJOANA ALEJANDRE, S. Las leyes... op cit., pp. 94-96. Para sintetizar esta doble protección de la que hablábamos, la citada autora alude a su compañero BERCOVITZ RODRÍGUEZ-CANO, el cual afirma que "la protección de los derechos exclusivos y la protección contra la competencia desleal forman dos círculos concéntricos, de manera que el círculo interior equivaldría a la protección de los derechos exclusivos, una protección más fuerte y sólida, y el círculo exterior equivaldría al de la protección por competencia desleal, menos sólida pero más amplia”.
} 
entre las legislaciones de los Estados miembros en dicha materia. La publicidad no tiene unos límites establecidos, sino que rebasa las fronteras de los Estados miembros $\mathrm{y}$, por ello, tiene una incidencia directa en el establecimiento y buen funcionamiento del mercado interior. Además de ello, tanto la publicidad engañosa como la publicidad comparativa ilegal pueden ocasionar una distorsión de la competencia en el seno del mercado interior. Así lo establece la Directiva 2006/114/CE del Parlamento Europeo y del Consejo sobre publicidad engañosa y publicidad comparativa ${ }^{19}$, en sus considerandos 2 y 3 . Por ello fue preciso unificar las legislaciones de los Estados miembros en lo correspondiente a esta materia, pues si bien algunos Estados de la Unión admitían la publicidad comparativa, otros sin embargo, la prohibían.

Remontándonos a los orígenes de la regulación comunitaria en el ámbito de la publicidad comparativa, cabe decir que su primer antecedente no se encuentra en la Directiva 10 de septiembre de 1984, relativa a la aproximación de las disposiciones legales, reglamentarias y administrativas de los Estados miembros en materia de publicidad engañosa 20 ; pues ésta, solamente regulaba la publicidad falaz. Sin embargo, si bien no se encuadraba directamente la publicidad comparativa en la citada normativa, sí se empieza a hacer referencia a ella en las sucesivas modificaciones de la Directiva, pues ésta última se constituía como la primera fase para disciplinar ciertas figuras publicitarias, señalando el legislador comunitario en su exposición de motivos que "en una segunda fase deberá ocuparse de la publicidad desleal, así como, en caso necesario, de la publicidad comparativa”.

En las sucesivas modificaciones posteriores a la Directiva, se fue regulando poco a poco la publicidad comparativa. El primer paso, se llevó a cabo mediante la Directiva de 6 de octubre de 1997, la cual tenía como objetivo armonizar la

\footnotetext{
19 Directiva 2006/114/CE del Parlamento Europeo y del Consejo, de 12 de diciembre de 2006, sobre publicidad engañosa y publicidad comparativa. "DOUE" núm. 376, de 27 de diciembre de 2006 (DOUE-L-2006-82663).

20 Directiva del Consejo, de 10 de septiembre de 1984, relativa a la aproximación de las disposiciones legales, reglamentarias y administrativas de los Estados miembros en materia de publicidad engañosa. "DOUE" núm. 250, de 19 de septiembre de 1984 (DOUE-L-984-80507).
} 
regulación de la publicidad comparativa en la Unión Europea ${ }^{21}$. A este respecto, se impusieron argumentos tales como que dicha figura publicitaria era favorable para la competencia como el hecho de que constituye "una manera legítima de informa a los consumidores de las ventajas que pueden obtener".

Posteriormente, el régimen jurídico de la publicidad comparativa fue variado a través de la Directiva de 11 de mayo de 2005, sobre prácticas comerciales desleales de las empresas en sus relaciones con los consumidores 22 .

Teniendo en cuenta la Directiva de 1984, así como sus consiguientes modificaciones, el legislador comunitario vio conveniente su codificación, dando lugar a la antes mencionada Directiva de 12 de diciembre de 2006.

Siguiendo al profesor LEMA DEVESA ${ }^{23}$, tenemos que decir que la citada Directiva es en cuanto a la publicidad comparativa es una Directiva "de máximos", lo cual quiere decir que no se pueden establecer requisitos posteriores para la admisión de esta figura publicitaria. Así pues, para velar por la licitud de esta modalidad es necesario que esos requisitos se cumplan en su totalidad, respetando en todo momento lo dispuesto en otras disposiciones comunitarias, y concretamente, en el Reglamento de 20 de marzo de 2006, relativo a la protección de las indicaciones geográficas y de las denominaciones de origen de los productos agrícolas y

\footnotetext{
21 Directiva 97/55/CEE del Parlamento Europeo y del Consejo, de 6 de octubre de 1997, por la que se modifica la Directiva 84/450/CEE sobre publicidad engañosa a fin de incluir en la misma la publicidad comparativa. "DOUE" núm. 290, de 23 de octubre de 1997 (DOUE-L-1997-81962).

22 Directiva 2005/29/CE del Parlamento Europeo y del Consejo, de 11 de mayo de 2005, relativa a las prácticas comerciales desleales de las empresas en sus relaciones con los consumidores en el mercado interior, que modifica la Directiva 84/450/CEE del Consejo, las Directivas 97/7/CE, 98/27/CE y 2002/65/CE del Parlamento Europeo y del Consejo y el Reglamento (CE) no 2006/2004 del Parlamento Europeo y del Consejo (Directiva sobre las prácticas comerciales desleales). "DOUE” núm. 149, de 11 de junio de 2005 (DOUE-L-2005-81047).
}

23 LEMA DEVESA, C., “La publicidad comparativa en la Unión Europea”, en Nueva Época, número 16, 2014. 
alimenticios $^{24}$, así como la Directiva de 21 de diciembre de 1988, relativa a la aproximación de las disposiciones de los Estados miembros en materia de marcas 25 .

Así las cosas, es momento de definir la propia publicidad comparativa. Para ello, es preciso citar el artículo 2, apartado c), de la Directiva de 2006, el cual define esta modalidad publicitaria como "toda publicidad que alude explícitamente o implícitamente a un competidor o a los bienes o servicios ofrecidos por un competidor". Este concepto ha despertado numerosas críticas en el seno de la doctrina, entre ellas, como nos comenta el citado autor, la del profesor TATO PLAZA que considera publicidad comparativa "aquella publicidad en la que el empresario anunciante compara su oferta con la de uno o varios competidores, identificados o inequívocamente identificables, con el resultado directo o indirecto, de resaltar las ventajas de los propios productos o servicios frente a los ajenos".

En reiterada jurisprudencia del TJUE se ha aludido a la definición dada por la Directiva de 2006, en concreto, podemos mencionar el fundamento 42 de la Sentencia de 12 de junio de 2008 (caso O2 (UK)), en el cual se hace referencia al mencionado art. 2 c) de la Directiva, diciendo que se trata de "una definición amplia que permite abarcar todas las formas de publicidad comparativa, de manera que, para que exista publicidad comparativa basta con que exista una comunicación que haga referencia, aunque solo sea implícitamente, a un competidor o a los bienes o servicios de éste"26.

\footnotetext{
24 REGLAMENTO (CE) no 561/2006 del Parlamento Europeo y del Consejo, de 15 de marzo de 2006, relativo a la armonización de determinadas disposiciones en materia social en el sector de los transportes por carretera y por el que se modifican los Reglamentos (CEE) $n^{\circ} 3821 / 85$ y (CE) $n^{\circ} 2135 / 98$ del Consejo y se deroga el Reglamento (CEE) n 3820/85 del Consejo. "DOUE” núm. 102, de 11 de abril de 2006 (DOUE-L-2006-80632).

25 Primera Directiva del Consejo, de 21 de diciembre de 1988, relativa a la aproximación de las legislaciones de los Estados miembros en materia de marcas. "DOUE” núm. 40, de 11 de febrero de 1989 (DOUE-L-1989-80075).

26 Véanse las SSTJCE Toshiba Europe (TJCE 2001, 295) apartados 30 y 31; de 8 de abril de 2003 (TJCE 2003, 99) , Pippig Augenoptik, C-44/01, apartado 35 y de 19 de abril de 2007 (TJCE 2007, 77), de Landtsheer Emmanuel, C-381/05, apartado 16.
} 
Por tanto, para que exista publicidad comparativa basta con que se aluda, ya sea explícita o implícitamente, a uno o varios competidores o incluso a los bienes o servicios de éstos, siempre que sea posible identificar a través de los mismos a la empresa titular del producto o servicio o los propios productos o servicios que la misma oferta.

En base a todas estas cuestiones, el TJUE nos aclara ciertos aspectos sobre esta figura publicitaria en su Sentencia de 19 de abril de 200727 (caso Landtsheer), al establecer, en primer lugar, que el simple hecho de que una empresa únicamente haga referencia, en su mensaje publicitario, a un tipo de productos no permite excluir a priori dicho mensaje del ámbito de aplicación de la Directiva (fundamento 18). Tal mensaje puede constituir publicidad comparativa en la medida en que se pueda identificar a un competidor o los bienes o servicios que éste ofrezca porque dicha publicidad aluda concretamente a ellos, aunque sea de modo implícito (fundamento 19). Corresponde al órgano jurisdiccional nacional verificar en cada caso concreto, una vez analizados todos los factores que conciernen al asunto, si una publicidad permite que los consumidores identifiquen, explícita o implícitamente, a una o varias empresas determinadas o los bienes o servicios que éstas suministra, por el hecho de que dicha publicidad aluda concretamente a ellos (fundamento 22).

Como puede advertirse, en la Unión Europea no se admite siempre y en todo caso la publicidad comparativa sino que para que sea aceptada debe cumplir unos requisitos de licitud contemplados por el legislador comunitario. Como expresa la STJUE de 18 de noviembre de $2010^{28}$ (caso Lidl SNC) "la licitud de la publicidad comparativa en toda la UE debe apreciarse únicamente a la luz de los criterios establecidos por el legislador de la Unión”.

\footnotetext{
27 STJUE (Sala $1^{\text {a }}$ ), de 19 de abril de 2007 (TJCE 2007/77).

28 STJUE (Sala 4a), de 18 de noviembre de 2010 (TJCE 2010/351).
} 
Así pues en consonancia con lo dicho, y en base al art. 4 de la Directiva de 2006, la publicidad comparativa estará permitida cuando cumpla las condiciones que se establecen en el citado precepto 29 .

Por otro lado, haciendo referencia a los recursos existentes, la Directiva en su artículo 5, dice que los Estados miembros velarán porque existan medios adecuados y eficaces accesibles a las personas u organizaciones con un interés legítimo para que puedan emprender judicialmente una acción o recurso administrativo para luchar contra la publicidad ilegal (entre ella, la publicidad engañosa y la comparativa que no cumpla los requisitos de licitud).

En último lugar, podemos resaltar que la publicidad comparativa no goza, como es obvio, del mismo nivel de aceptación en todos los países. Pues si bien, en algunos está prohibida, en otros no sólo está permitida sino que existe una larga tradición en su uso. Este último es el caso de Estados Unidos, donde dicha figura publicitaria está ampliamente difundida. Ejemplo de ello son las numerosas campañas publicitarias que enfrentan a grandes marcas como Coca-Cola con Pepsi o Burger King con Mc Donal's, donde la modalidad de publicidad comparativa está continuamente presente.

De esta forma, podemos señalar que la publicidad comparativa tiene como objetivo resaltar las diferencias del producto que se promociona con las del competidor. De tal forma, que el producto que se contrapone al anunciado quede

\footnotetext{
29 PUGA GÓMEZ, S., "Publicidad engañosa y publicidad comparativa. Sentencia del Tribunal de Justicia de 8 de abril de 2003 (TJCE 2003, 99). Adaptación de la normativa española a las directivas comunitarias”, en Actualidad Jurídica Aranzadi, número 706, 2006. Tales condiciones son: a) que no sea engañosa en relación a lo dispuesto en la normativa comunitaria; b) que compare bienes o servicios que satisfagan las mismas necesidades o tengan la misma finalidad; c) que compare de modo objetivo una o más características esenciales, pertinentes, verificables y representativas de dichos bienes y servicios, entre las que podrá incluirse el precio;

d) que no desacredite ni denigre los signos distintivos, bienes, servicios, actividades u otras circunstancias de algún competidor $^{29}$; e) que se refiere en cada caso, en productos con denominación de origen, a productos con la misma denominación; f) que no obtenga indebidamente ventaja de la reputación de un signo distintivo de un competidor o de las denominaciones de origen de productos competidores; g) que no presente un bien o un servicio como imitación o réplica de un bien o servicio con una marca o un nombre comercial protegidos; h) que no dé lugar a confusión entre los comerciantes, entre el anunciante y un competidor o entre las marcas, los nombres comerciales, otros signos distintivos o los bienes o servicios del anunciante y los demás de algún competidor.
} 
cualitativa o cuantitativamente por debajo de aquel, obteniendo el anunciante, de dicha comparación un resultado beneficioso, al resaltar la superioridad de su producto o servicio respecto al de su oponente.

Además, como dice el profesor RICARDO PAREDES30 "existe una tendencia mundial a reconocer, tanto analítica como prácticamente, por las instituciones reguladoras, que la publicidad comparativa tiene la potencialidad de reducir barreras a la entrada y aumentar la competencia en los mercados. No obstante, en la práctica la publicidad comparativa en la mayoría de los países, particularmente en los de menor desarrollo, es muy limitada o inexistente".

Aquel refrán popular que decía que las comparaciones son odiosas es cierto, pero no lo es menos que en el caso de la publicidad, puede ser beneficiosa. Sería preciso desterrar la idea de que cualquier comparación es mala o ilícita. La comparación, respetando ciertos límites y determinados requisitos, puede ser productiva, tanto para los consumidores que ven satisfecho su derecho a la libertad de elección sopesando las ventajas e inconvenientes de los productos o servicios, como para el propio mercado que se vuelve más competitivo, incluso para las empresas competidoras que intentan superar su nivel y el del resto.

\subsection{Publicidad ilícita.}

Decía ÓSCAR WILDE: "Sólo hay una cosa en el mundo peor que estar en boca de los demás, y es no estar en boca de nadie". Esta reflexión parece ser la máxima de muchos empresarios y anunciantes, pues son capaces de vulnerar la legislación vigente, unas veces de forma muy sutil y otras no tanto, para llamar la atención del receptor. Claro está, que este riesgo lo asumen porque comporta la

30 RICARDO PAREDES, M., "Fundamentos para la regulación de la publicidad comparativa", en Revista Abante, Vol. 7, 1 (abril 2004), pp. 67-102. 
expectativa de un beneficio aún mayor: aumentar las ventas del producto publicitado y conseguir fieles clientes.

Podríamos decir que esta frase define, sin ánimo de generalizar, a bastantes empresarios. Las empresas persiguen ganancias, maximizar los beneficios reduciendo los costes, suele ser su lema matriz. Dentro de éstas, por supuesto, habrá algunas más sensibilizadas con el medio ambiente o que ostenten una mayor conciencia social, en este apartado nos centramos más en esas empresas menos consecuentes con la realidad en la que vivimos.

Tal como venimos diciendo, los empresarios y profesionales, que en cuanto comercializan con sus productos y servicios, quieren darlos a conocer y distinguirlos de los demás a través de las marcas de las que son titulares, necesitan de una herramienta que actúe como medio de difusión de las mismas, y ésta es la publicidad, una vía de propagación de masas.

Por tanto, la publicidad de su marca les ha de suponer un beneficio, de lo contrario habría que preocuparse pues algo no se estaría haciendo bien, si con su campaña publicitaria o de marketing no llaman la atención del consumidor, repercutiendo en la compra, hay algún eslabón perdido o roto. La publicidad tiene el objetivo de atraer la atención del consumidor, que vayan al supermercado, tienda de ropa, joyería... vean todos los productos de los mismos, y les llame la atención aquél que vieron en un panfleto, en un anuncio en televisión o escucharon en la radio. Y de entre todos, decidan comprar ese. Pues bien, ¿cómo se difunde ese producto a través de su publicidad? Puede ser por su masiva emisión, por su pegadiza melodía o su especial constitución..., pero también puede propagarse por el denominado "boca a boca”. Y esa última difusión no es menos importante que las demás, las personas comentan unas con otras en la calle, pero también a través de redes sociales, considerable medio de difusión en la actualidad, o a través de cualquier otro medio de comunicación, y ese método de propagación infunde ventajas o desventajas a las marcas. Ventajas si la difusión es su mayoría buena o desventajas si se transmite una 
visión mala del producto. Sin embargo, si esa difusión de la marca publicitada no habla del producto en sí, sino más bien de la propia publicidad del mismo, crea una curiosidad en el consumidor, pues no me están diciendo que el producto sea defectuoso, o simplemente malo, me están transmitiendo la campaña publicitaria de esa marca, de la cual se está hablando en determinados foros, y cuando paso por alguna tienda donde se comercie con esa marca, la contemplo porque me recuerda a ese anuncio del que tanto están hablando mis amigos, o en la televisión o en Internet... Al final puede ser que "la curiosidad mate al gato" y lo compre porque me haya llamado la atención tanto revuelo a través de su campaña publicitaria. Esto es lo que quiere tanto la agencia de publicidad como el anunciante como el titular de la marca, y para ello recurre a veces a una publicidad desleal, contraria al ordenamiento jurídico y sancionada por el mismo.

No es preciso vulnerar las normas para alcanzar una buena publicidad, porque ésta no se reduce a algo tan simple: captar al receptor sea como sea, aunque se haga denigrando o engañando a los consumidores. La publicidad es mucho más que eso, consagra el ingenio y la empatía como principios básicos de su trabajo. Un buen publicista es aquél capaz de ponerse en la piel del consumidor a quien quiere dirigir su campaña, capaz de captar sus deseos y de llamarle la atención en menos de un minuto, sin agredir su sensibilidad ni la conciencia social. A este respecto, nos viene a la memoria una anécdota contada por LUIS BASSAT ${ }^{31}$,que creemos resume lo que debe ser la buena publicidad.

\footnotetext{
31 BASSAT, L., El libro rojo de la publicidad: ideas que mueven montañas, De Bolsillo, 2013, pp. 9-10. "Un día vino a verme José María Usandizaga, ginecólogo vasco con el que me une una gran amistad. Su hijo acababa de sufrir una operación en los ojos. Todo había ido bien. Pero le preocupaba que el niño no los abriera todavía, por ese temor al dolor tan instintivo y tan humano. Y era vital que lo hiciera cuanto antes, para favorecer la cicatrización. Aparenté no darle ninguna importancia al tema, y les invité a bajar al garaje para enseñarles la moto de montaña que me acababa de comprar. “Habéis visto qué Montesa roja más bonita me he comprado? Es el último modelo”. No hizo falta añadir mucho más. Los ojos del niño José Mari se abrieron como por arte de magia. Sus ganas de ver la moto fueron superiores al dolor que durante tres días le había obligado a vivir a ciegas. No soy psicólogo ni lo pretendo. Ni un encantador de serpientes. Ni un médico. Pero conozco al ser humano. Y supe adivinar que, para que el niño abriera los ojos, no había que pedírselo ni exigírselo. Ni tampoco argumentarle que así se curaría antes. Ni siquiera explicarle que, si lo hacía, vería la moto más fabulosa del mundo. Había que olvidarse de los ojos por completo, y seducirle, convencerle de que se encontraba ante una moto realmente fantástica. Los ojos se abrieron solos, casi sin querer, de forma automática, como automática es la reacción de la gente ante la buena publicidad".
} 
Así pues, llegados a este punto, nos podemos preguntar ¿qué límite existe a la hora de hacer publicidad de un producto? ¿todo vale por alcanzar el máximo beneficio? Lógicamente, la respuesta es no. No todo vale para conseguir las mejores y mayores ventas.

Cuando se traspasa el límite de lo legalmente establecido es cuando derivamos en el terreno de la publicidad ilícita. Para conocer qué publicidad es consignada por el ordenamiento jurídico como ilícita nos debemos referir al artículo 3 de la Ley General de Publicidad, el cual dice establece como ilícita 32.

Tras la regulación procedente de la Ley 29/200933, se modifica el régimen jurídico contenido tanto en la LGP como en la LCD, de tal forma que la primera remite a la segunda para la regulación de la publicidad ilícita. Por su parte, el art. 18 LCD contempla una cláusula general, que califica de desleal a toda la publicidad reconocida como ilícita por la LGP, no solamente la publicidad engañosa, desleal y agresiva que recoge el art. 3 e) de la propia LGP. Así pues, tras esta reforma de la legislación aplicable, será reputada no sólo de ilícita sino también de desleal toda publicidad encuadrable en el art. 3 LGP.

\footnotetext{
32 “a) La publicidad que atente contra la dignidad de la persona o vulnere los valores y derechos reconocidos en la Constitución, especialmente a los que se refieren sus artículos 14, 18 y 20, apartado 4. Se entenderán incluidos en la previsión anterior los anuncios que presenten a las mujeres de forma vejatoria o discriminatoria, bien utilizando particular y directamente su cuerpo o partes del mismo como mero objeto desvinculado del producto que se pretende promocionar, bien su imagen asociada a comportamientos estereotipados que vulneren los fundamentos de nuestro ordenamiento coadyuvando a generar la violencia a que se refiere la Ley Orgánica 1/2004, de 28 de diciembre, de Medidas de Protección Integral contra la Violencia de Género. b) La publicidad dirigida a menores que les incite a la compra de un bien o de un servicio, explotando su inexperiencia o credulidad, o en la que aparezcan persuadiendo de la compra a padres o tutores. No se podrá, sin un motivo justificado, presentar a los niños en situaciones peligrosas. No se deberá inducir a error sobre las características de los productos, ni sobre su seguridad, ni tampoco sobre la capacidad y aptitudes necesarias en el niño para utilizarlos sin producir daño para sí o a terceros. c) La publicidad subliminal. d) La que infrinja lo dispuesto en la normativa que regule la publicidad de determinados productos, bienes, actividades o servicios. e) La publicidad engañosa, la publicidad desleal y la publicidad agresiva, que tendrán el carácter de actos de competencia desleal en los términos contemplados en la Ley de Competencia Desleal"

33 Ley 29/2009, de 30 de diciembre, por la que se modifica el régimen legal de la competencia desleal y de la publicidad para la mejora de los consumidores y usuarios. "BOE" núm. 315, de 31 de diciembre de 2009 (BOE-A2009-21162).
} 
Cabe hacer un pequeño inciso a este respecto de la consideración de la publicidad ilícita como comportamiento desleal, y es que se reputará como tal, todo aquel que resulte objetivamente contrario a las exigencias de la buena fe (art. 4.1 LCD). Será publicidad no sólo ilícita sino también desleal, aquella contraria a las exigencias de la buena fe, que tiene lugar cuando en las relaciones con consumidores y usuarios el comportamiento (incluyendo la publicidad) de un empresario o profesional es contrario a la diligencia profesional, entendida ésta como el nivel de competencia y cuidados especiales que cabe esperar de un empresario conforme a las prácticas honestas del mercado, de tal forma que distorsione o pueda distorsionar de manera significativa el comportamiento económico del consumidor medio o del miembro del grupo destinatario de la práctica comercial si ésta va dirigida a un grupo concreto de consumidores (art. 4.1 LCD).

Como última consideración previa al análisis de algunos supuestos de publicidad ilícita mencionados, solo recordar que, para valorar la posible ilicitud de una pieza publicitaria, la legislación establece como referencia la interpretación que de ella pueda realizar un consumidor medio, normalmente informado y razonablemente atento y perspicaz, del círculo de destinatarios al que vaya dirigida la publicidad 34 .

\subsection{Publicidad atentatoria.}

El apartado a) del art. 3 LGP considera ilícita la publicidad que vulnere el contenido de la Constitución Española, lo cual no hace sino plasmar en la Ley un contenido generalmente aceptado y conocido, como es que cualquier atentado contra los valores y principios constitucionalmente reconocidos es reprobable en nuestro ordenamiento y puede acarrear consecuencias jurídicas. Sin embargo, en este ámbito de la ilicitud publicitaria la controversia va más allá, no se trata sólo de no infringir los derechos constitucionalmente avalados, sino de poner en una balanza esos derechos y la libertad de expresión, ambos derechos fundamentales, que para su juicio

34 VILAJOANA ALEJANDRE, S. Las leyes de la publicidad... op cit., pp. 54-55. 
requiere de la ponderación del Tribunal. Como decíamos al principio, de este apartado, no todo vale para conseguir un propósito y, en este caso el fin no puede justificar nunca los medios si por el camino se vulneran los derechos de otras personas. Por ello, el apartado a) del art. 3 se refiere concretamente a ciertos derechos fundamentales, sin exclusión del resto, pues no estamos ante un numerus clausus, ya que el propio precepto acoge el vocablo "especialmente" para referirse a los derechos que enuncian.

Así pues, realiza una lista enunciativa aludiendo en primer lugar a la dignidad de la persona (art. $10 \mathrm{CE}$ ), el derecho a la igualdad (art. $14 \mathrm{CE}$ ), derecho al honor, la intimidad personal y familiar y a la propia imagen (art. $18 \mathrm{CE}$ ) y a la protección de la juventud y la infancia (art. 20.4 CE). La especial alusión a estos derechos en el precepto es consecuencia de su vulnerabilidad y sensibilización en la materia que protegen. Así pues, realmente los campos especialmente protegidos por el precepto han sido durante la historia lo más castigados con el uso de los medios de comunicación, lo cual se ha traducido en diversos pronunciamientos judiciales y extrajudiciales, así como en campañas de rechazo contra el uso de estos derechos para alcanzar fines económicos, con campañas publicitarias que han denigrado, vejado y discriminado a ciertos colectivos, infringiendo de esta forma no sólo el ordenamiento jurídico, sino los valores y principios morales al degradar a la persona a la categoría de objeto.

Para empezar, debemos hacer hincapié en la publicidad discriminatoria en razón de sexo, la cual ha ocupado muchas campañas publicitarias a lo largo de los años, creando estereotipos sobre la imagen de la mujer, muchas veces crueles y vejatorios. El propio art. 3 LGP ha incluido en su aparado a), un segundo párrafo introducido por la Ley Orgánica contra la Violencia de Género de 200435, el cual dice: "Se entenderán incluidos en la previsión anterior los anuncios que presenten a las mujeres de forma vejatoria o discriminatoria, bien utilizando particular y

35 Ley Orgánica 1/2004, de 28 de diciembre, de Medidas de Protección Integral contra la Violencia de Género. "BOE" núm. 313, de 29 de diciembre de 2004 (BOE-A-2004-21760). 
directamente su cuerpo o partes del mismo como mero objeto desvinculado del producto que se pretende promocionar, bien su imagen asociada a comportamientos estereotipados que vulneren los fundamentos de nuestro ordenamiento coadyuvando a generar la violencia a que se refiere la Ley Orgánica 1/2004, de 28 de diciembre, de Medidas de Protección Integral contra la Violencia de Género”. Esta previsión no es baladí, pues trae causa en innumerables comportamientos que encorsetan a la mujer, considerándola inferior al hombre y en muchos casos contemplándola como un objeto o como un ser sin voz ni voto. A ello se suma la lacra social que padecemos denominada "violencia de género", ya que cada año mueren muchas mujeres en manos de sus parejas, muchas veces tras un largo maltrato físico y psicológico. Si además prorrogamos en los medios, en este caso a través de la publicidad, la situación de inferioridad, incluso inutilidad de la mujer para actuar en la vida social, económica y jurídica, limitándola a la familiar, ello derivará en un clima de discriminación constante que se transmitirá de generación en generación, pues la publicidad es vista por niños, adultos y ancianos. Entonces, es preciso tomar medidas para paliar esta situación y no contribuir con actos de este tipo a propagar la discriminación, de ningún tipo, porque por mucho que se gane en una campaña no es comparable con lo que se puede perder a nivel moral, social y humano.

A lo largo de la historia han sido numerosas las campañas publicitarias denigratorias y vejatorias para la mujer, a ellas han recurrido distintos empresarios, tanto grandes firmas como pequeñas marcas.

En este ámbito de publicidad ilícita de carácter discriminatorio en razón del sexo, es de gran importancia la Sentencia de 5 de diciembre de 2013, del Juzgado de lo Mercantil de Málaga (Sección $2^{\mathrm{a}}$ ), caso Ryanair 36 , pues no existe mucha jurisprudencia sobre este ámbito, y ello a pesar de las reiteradas campañas publicitarias discriminatorias que se han realizado, pues muchos casos no llegan a los Tribunales si no que se resuelven a instancia anteriores mediante procedimientos de solución extrajudicial de conflictos, con base a la autorregulación publicitaria o por

\footnotetext{
36 Sentencia del Juzgado de lo Mercantil de Málaga de 5 de diciembre de 2013 (JUR 2013/375143).
} 
presión de organizaciones como el Instituto de la Mujer u organizaciones de consumidores y usuarios. En el asunto que trae causa se vulnera propiamente el art. 3 a) LGP.

En palabras de la profesora RODRÍGUEZ GONZÁLEZ ${ }^{37}$, se ha observado un cierto cambio en la publicidad que atañe a mujeres, el cual coincide, desde el punto de vista cronológico con la modificación introducida en el art. 3 a) LGP pro la Ley de 2004, y una mayor atención y sensibilidad en la materia, apoyada por trascendentales Resoluciones del Jurado de Autocontrol de la Publicidad por su alto valor simbólico y ejemplar, además de su vinculación con empresas que han prestado su consentimiento para trasladar sus conflictos al seno de Autocontrol. A pesar de este cambio, siguen existiendo campañas publicitarias que atentan contra la dignidad de la mujer, aunque parece que ha aumentado la sensibilización y concienciación respecto a la materia, así como, la repulsión ante este tipo de ilícitos.

La sentencia sobre el caso Ryanair se sustenta en la pretensión de declarar como ilícita y desleal la publicidad de la compañía aérea expuesta a través de su web de una campaña denominada "Tarifas al rojo vivo" "Y la tripulación". Así como un calendario que se promocionaba en la misma web, titulada "Las chicas de Ryanair. Calendario Benéfico de la tripulación de cabina 2013”. La Magistrada realiza un minucioso análisis sobre la discriminación sexista en la publicidad, aludiendo a diversas resoluciones de organismos administrativos de autorregulación publicitaria a nivel nacional como internacional, como el Jurado de Autocontrol en España. En concreto, en su fundamento jurídico sexto recoge doctrina del citado órgano, el cual estima que la mera representación del cuerpo humano o la provocación sugerente no implican la violación de la dignidad de la persona, pues según plantea "España se asienta ante una sociedad muy plural, abierta, moderna, permisiva y tolerante, con disparidad de criterio”. Pero tras esta regla incluye una excepción a esa premisa:

37 RODRÍGUEZ GONZÁLEZ, A., "Reformas pendientes y andantes en publicidad ilícita discriminatoria. A propósito de la Sentencia Ryanair", en Revista de Derecho de la Competencia y la Distribución, número 14, Comentarios de jurisprudencia, La Ley. 
"salvo cuando la representación que se haga del mismo resulte vejatoria, procaz o pornográfica". Consiguientemente, el Jurado introduce un requisito que condiciona la regla anterior, al establecer que no deberán concurrir en la publicidad elementos ajenos al desnudo en sí, en los que se pudiera apreciar una vulneración de algún derecho fundamental de la mujer por presentarla.

A pesar del punto de inflexión marcado por la regulación en la LGP, la sentencia del caso Ryanair y la legislación sobre vigente en materia de igualdad 38 , aún hoy siguen existiendo campañas publicitarias que denigran en razón del sexo.

Por otro lado, existe publicidad discriminatoria contra la figura del hombre, la cantidad es mucho menor que en el caso de la mujer, pero es cierto que ha habido marcas que se han decantado por este tipo de publicidad, en las que igualmente se denigra y veja al hombre, degradándolo y cosificándolo. Así lo reflejan anuncios como el de la marca de ropa KOOKAÏ, en el que distinguimos a un hombre dentro de una pecera y una mujer echándole comida. Claramente se está pintando al hombre como una persona dependiente sometido a la voluntad de la mujer, que en esta estampa aparece en una posición de superioridad respecto a aquél, jugando con él y utilizándolo como mascota. Es una forma de decir que con la ropa de la citada marca podrás manejar a cualquier hombre a tu antojo.

Otro de este tipo lo vemos en la publicidad emitida por la marca de NMA, en la que un zapato de tacón atraviesa a un hombre. Este anuncio fue prohibido en el Reino Unido en 2004, por banalizar la violencia, ser degradante y sexista 39.

\footnotetext{
38 Vid. Ley Orgánica 3/2007, de 22 de marzo, para la igualdad efectiva de hombres y mujeres. "BOE" núm. 71, de 23 de marzo de 2007 (BOE-A-2007-6115).

39 Véase DIEZ, P., "Los 10 anuncios más discriminatorios contra el hombre", en United Explanations. http://www.unitedexplanations.org/2014/05/12/los-10-anuncios-mas-discriminatorios-contra-el-hombre/, 12 de mayo de 2014.
} 
No es grato decir que sigue realizándose publicidad de este tipo, ni que hay una cierta tendencia a llamar la atención de los consumidores de la forma que sea, utilizando la vía de la degradación y la discriminación en el proceso, para alcanzar una cuota mayor de beneficios económicos y popularidad, pero los hechos evidencian que esto está ocurriendo. Si bien, cada vez son más las organizaciones de usuarios y consumidores como FACUA o determinados organismos que protegen a ciertos colectivos como el Instituto de la Mujer, que alzan la voz en contra de estos ilícitos. Quizás todos debemos contribuir a este objetivo de minimizar esta publicidad ilícita hasta erradicarla, no formando parte de sus beneficios.

Por otro lado, pero dentro de este art. 3 a) LGP encontramos la protección frente a la publicidad ilícita de los derechos al honor, a la intimidad familiar y personal y a la propia imagen (art. $18 \mathrm{CE}$ ), cuyo desarrollo normativo se contiene en la Ley Orgánica 1/1982, de 5 de mayo, de protección civil del derecho al honor, a la intimidad personal y familiar y a la propia imagen 40 . Así pues, esta Ley en su artículo 2.1 establece que la protección de los citados derechos "quedará delimitada por las leyes y por los usos sociales atendiendo al ámbito que, por sus propios actos mantenga cada persona reservado para sí mismo o su familia”. A su vez, alude a la no consideración de intromisión ilegítima, terreno que nos atañe en la publicidad pues puede marcar la línea entre la legalidad y la ilicitud, cuando medie autorización expresa en la Ley o cuando el titular hubiere prestado su consentimiento (art. 2.2).

En el siguiente apartado, el artículo 3 b) $\mathrm{LGP}^{41}$, nos habla de la protección de los menores frente a la publicidad, lo que también hace en el apartado a) al citar el art. 20.4 CE que ampara la tutela de la juventud y la infancia. Podemos decir que el legislador incide en la protección de los menores 42 por considerarlo un colectivo más

\footnotetext{
40 Ley Orgánica 1/1982, de 5 de mayo, de protección civil del derecho al honor, a la intimidad personal y familiar y a la propia imagen. "BOE" núm. 115, de 14 de mayo de 1982 (BOE-A-1982-11196).

41 Apartado añadido a través de la reforma cometida por la Ley 29/2009.

42 Muestra de este especial interés del legislador respecto a la figura del menor, es la Ley Orgánica 1/1996, de 15 de enero, de Protección Jurídica del Menor, de modificación parcial del Código Civil y de la Ley de Enjuiciamiento Civil (BOE-A-1996-1069), la cual establece, trasladándonos al ámbito publicitario, que "para garantizar que la
} 
vulnerable al encontrarse en una fase temprana de su desarrollo tanto físico como psíquico y emocional, impresionable fácilmente debido a su inocencia. Por ello, su protección es un objetivo prioritario, de ahí la doble incisión del legislador en el articulado de la LGP. Esta regulación contenida en la LGP en torno a la figura del menor de bifurca en dos caminos: por un lado, se pretende proteger al menor como receptor o destinatario de la publicidad y, por otro, se intenta evitar abusos en la utilización de la imagen de los menores en el ámbito publicitario.

\subsection{Publicidad subliminal.}

La siguiente modalidad que recoge la LGP es la publicidad subliminal (art. 3 c)), la cual es definida por dicho texto legal en su artículo 4 que dice: "A los efectos de esta Ley, será publicidad subliminal la que mediante técnicas de producción de estímulos de intensidades fronterizas con los umbrales de los sentidos y análogas, pueda actuar sobre el público destinatario sin ser conscientemente percibida”. El precepto no deja lugar a dudas, en términos coloquiales, la publicidad subliminal es aquella que percibimos sin darnos cuenta.

En cuanto se transmite esa publicidad de modo inconsciente en la persona del destinatario, esa transmisión imperceptible es la característica que otorga el carácter ilícito a la publicidad. Todo mensaje publicitario debe ser recibido de forma consciente por el destinatario, de manera que la incitación subliminal a consumir un determinado producto o a realizar una cierta conducta, es reprochada por el legislador, puesto que lo que subyace bajo este tipo de mensajes es el deseo de manipular al consumidor 43 .

Sin embargo, aunque no somos muy conscientes de ello, constantemente nos abordan mediante estímulos a través de los medios de comunicación, como en el cine,

publicidad o mensajes dirigidos a menores o emitidos en la programación dirigida a éstos, no les perjudique moral o físicamente, podrá ser regulada por normas especiales" (art. 5.4).

43 BARONA VILAR, S., Tutela civil y penal de la publicidad, Tirant lo Blanch y Universitat de València, Valencia, 1999, pp. 120-121. 
en el teatro o en la propia música, para que consumamos un determinado producto, actuemos de una determinada forma, o creamos un determinado criterio. La realidad es que muchas veces a través de la publicidad subliminal los empresarios mueven sus hilos, manejando como marionetas en el escenario comercial a los consumidores receptores del mensaje publicitario.

La publicidad subliminal emite mensajes al subconsciente del destinatario, que puede ser un mero espectador o un potencial consumidor. A priori es difícil captar este tipo de publicidad, aún menos cuando se emite en una película, serie o en anuncio, donde la rapidez del movimiento dificulta la apreciación; en algunos casos de forma detenida se pueden vislumbrar este tipo de mensajes, pero en otros casos es casi imposible para un espectador o consumidor medio o común, no lo es para los publicistas y expertos en la materia. Podemos comprobar que muchos de estos mensajes son relativos a ciertas prácticas o posturas sexuales o al sexo en general, otros en cambio acerca del consumo de una determinada marca (como vemos en el caso de la película de el "Señor de los Anillos", en la que en el famoso anillo se lee la palabra "Coca Cola" o en la serie de televisión "House", donde aparece el protagonista con su ordenador de la marca “Apple").

Al igual que es difícil percibir conscientemente este tipo de publicidad, también es complicado probar su existencia, por ello, como apunta la VILAJOANA ALEJANDRE $^{44}$, un sector doctrinal aboga por suprimir esta modalidad de ilícito publicitario, pues quedaría incluida en las modalidades precedentes, ya que esta publicidad afecta a la dignidad de la persona que no puede ser manipulada. Muestra de su escasa relevancia jurídica es que el tiempo de vigencia de la norma, el ilícito por publicidad subliminal no ha sido causa de ningún pronunciamiento judicial, ninguna campaña publicitaria ha sido cesada o modificada por los Tribunales de Justicia en base a ello.

44 Vid. VILAJOANA ALEJANDRE, S. Las leyes de la publicidad..., p. 63. 
En otro orden de cosas y en cuarto lugar, la LGP declara como ilícita la publicidad que "infrinja lo dispuesto en la normativa que regule la publicidad de determinados productos, bienes, actividades o servicios" (art. 3 d)). A continuación, en su artículo 5 contempla la publicidad de esos ciertos bienes o servicios, en su mayoría material o productos sanitarios, pero también aquellos que puedan generar riesgos para la salud o seguridad de las personas o de su patrimonio, o se trate de publicidad sobre juegos de suerte, envite o azar. Todos ellos podrán ser regulados por una normativa especial o sometidos al régimen de autorización administrativa previa, este último también podrá regir la protección de valores y derechos reconocidos constitucionalmente cuando así lo requieran. Cabe incidir en que esta remisión a la normativa especial que regule la publicidad de los bienes y servicios a los que alude el art. 5 LGP, abre un amplio abanico de normas relativo de publicidad ilícita a tener en cuenta en cualquier litigio de estas características.

\subsection{Publicidad engañosa.}

En su aparado e) el art. 3 LGP alude a la publicidad engañosa, a la publicidad desleal y a la publicidad agresiva, remitiéndola a la LCD al otorgarles la consideración de actos de competencia desleal45 (arts. 18 y 19.1 LCD).

En cuanto a la primera de ellas, la denominada publicidad engañosa, cabe decir que goza de una amplia regulación a nivel comunitario 46 la cual ha sido traspuesta a nuestro ordenamiento jurídico a través de la Ley 29/2009.

Así pues, la Directiva 2006/114/CEE, del Parlamento Europeo y del Consejo, de 12 de diciembre de 2006, sobre publicidad engañosa y publicidad comparativa,

\footnotetext{
45 Dicha remisión trae causa en la reforma elaborada por la Ley 29/2009.

46 Directiva 2006/114/CEE, del Parlamento Europeo y del Consejo, de 12 de diciembre de 2006, sobre publicidad engañosa y publicidad comparativa (DOUE-L-2006-82663) que deroga a la Directiva del Consejo, de 10 de diciembre de 1984, relativa a la aproximación de disposiciones legales, reglamentarias y administrativas de los Estados miembros en materia de publicidad engañosa (DOUE-L-1984-80507).
} 
aborda en su artículo 2, apartado b) la definición de publicidad engañosa 47 , como una modalidad de publicidad ilícita contra la cual existen más pronunciamientos judiciales, pudiendo se ellola causa que afecta de modo directo a consumidores y usuarios, y de forma indirecta al resto de competidores, pues no el empresario que recurre a este tipo de ilícito, utilizando técnicas alejadas del Derecho, no actúa en el mercado de forma justa ni competitiva, sino de forma desleal. Es tal su repercusión que es la única modalidad castigada por el Código Penal, en su artículo 282,48 cuando suponga un perjuicio grave y manifiesto a los consumidores. Mientras no se cumpla lo establecido en el precepto pero siga siendo publicidad engañosa se estará a lo dispuesto en LCD para los actos de competencia desleal, en los que se incluye.

Por su parte, la LCD en su artículo 5.1, considera desleal por ser engañosa “cualquier conducta que contenga información falsa o información que, aun siendo veraz, por su contenido o presentación induzca o pueda inducir a error en los destinatarios, siendo susceptible de alterar su comportamiento económico”. Y además, es preciso que dicha conducta incida bien en la existencia o la naturaleza del bien o servicio, o en las características principales del bien o servicio, o en la asistencia posventa al cliente y el tratamiento de las reclamaciones, en el alcance de los compromisos del empresario o profesional, los motivos de la conducta comercial y la naturaleza de la operación comercial o el contrato, así como cualquier afirmación o símbolo que indique que el empresario o profesional o el bien o servicio son objeto de un patrocinio o una aprobación directa o indirecta, el precio o su modo de fijación, la necesidad de un servicio o de una pieza, sustitución o reparación, la naturaleza, características y derechos del empresario o profesional o su agente o los derechos legales o convencionales del consumidor.

\footnotetext{
47 Se entenderá por ésta "toda publicidad que, de una manera cualquiera, incluida su presentación, induce a error o puede inducir a error a las personas a las que se dirige o afecta y que, debido a su carácter engañoso, puede afectar su comportamiento económico o que, por estas razones, perjudica o es capaz de perjudicar al competidor".

48 Ley Orgánica 10/1995, de 23 de noviembre, del Código Penal. "BOE” núm. 281, de 24/11/1995 (BOE-A-199525444), cuyo artículo 282 ha sido modificado por la Ley 1/2015, de 30 de marzo, por la que se modifica la Ley anteriormente citada.
} 
También se consideran desleales las omisiones engañosas contenidas en el art. 7.1 LCD, es decir, la omisión y ocultación de información necesaria para que el destinatario pueda adoptar la decisión que más le convenga en relación a su economía, así como aquella información ininteligible, poco clara o ambigua. Para la consideración de un acto como engañoso se tendrá que analizar las circunstancias del caso concreto (art. 7.2).

Igualmente se reputan desleales por ser engañosas las prácticas que confundan a los consumidores y usuarios, incluyendo el riesgo de asociación, que afecten al comportamiento económico de los mismos (art. 20 LCD), las prácticas engañosas sobre códigos de conducta u otros distintivos de calidad recogidas en el art. 21, las prácticas señuelo y las prácticas promocionales engañosas del art. 22, las engañosas que versen sobre la naturaleza y propiedades de los bienes o servicios, su disponibilidad y los servicios posventa (art. 23), las de venta piramidal (art. 24), las prácticas engañosas por confusión (art. 25), las prácticas comerciales encubiertas (art. 26), así como otras prácticas recogidas en el art. 27.

Cabe resaltar que, las prácticas comerciales reguladas en los arts. 21 a 31, incluyendo, por tanto, todas las prácticas engañosas mencionadas anteriormente, se reputarán siempre como desleales con los consumidores en base al art. 19.2 LCD. Ello implica que si esas prácticas comerciales engañosas tienen lugar entre empresarios y profesionales, o en el caso de que ambas partes sean empresarios o profesionales, no tendrán la consideración de desleales de forma automática, sino que habrá que analizar a la luz de lo dispuesto en el art.5 del citado texto normativo.

\section{Conclusiones.}

El objetivo primordial de este trabajo ha sido acercarnos al funcionamiento del binomio marca-publicidad, incidiendo en los usos del citado signo distintivo y en los tipos de publicidad existentes, abordando las dimensiones que alberga dicha disciplina y en consonancia con las investigaciones doctrinales y jurisprudenciales 
existentes que tienen como finalidad la indagación y exploración de la unión de estos elementos y su repercusión mediata e inmediata en el mercado.

En este terrero juega un papel fundamental la publicidad, no solamente por su estrecha unión con la marca, sino porque de la misma nace una nueva relación con otro elemento fundamental en el tráfico económico, el cual es primordial para alcanzar el mayor objetivo del empresario titular de la marca y del empresario publicitario: conseguir o aumentar los beneficios. Este elemento esencial es el propio consumidor, que dependiendo del tipo de producto o servicio marcado que se difunda puede ser un consumidor medio o bien, un especialista en la materia que se oferta. Por tanto, podemos afirmar que esta triple relación de intereses encontrados es fundamental en el juego del mercado, pues si falta alguno de ellos puede crear para el resto graves distorsiones que afecten al tráfico económico, lo que puede beneficiar la competencia pero perjudicar al consumidor, que ve restringida su libertad de elección.

Pues bien, ante lo que parece ser una familia a priori bien avenida (marca, publicidad y consumidor), es preciso fijar algunas reglas para alcanzar un buen funcionamiento de la misma, para que dicho desarrollo sea no sólo legal, sino leal y honrado, acorde con pautas de competencia del tráfico mercantil, empresarial y económico. Hacer trampa o jugar sucio en este ámbito perjudica a todos los engranajes de la maquinaria, bien de forma directa o indirecta.

Por ello, para evitar estos problemas contamos no solamente con la legislación vigente relativa al derecho marcario, competencia desleal y publicidad, sino también con mecanismos de solución extrajudicial de conflictos, que han experimentado un elevado auge en los últimos tiempos, pues gozan de buenos resultados así como de un alto nivel de compromiso entre sus asociados. Entre estos mecanismos, debemos citar la denominada autorregulación o autodisciplina publicitaria, un sistema que reúne a empresarios involucrados en el sector publicitario que voluntariamente se someten a unas normas de conducta establecidas y amparadas por órganos independientes de control, con el objeto de alcanzar un ejercicio de la actividad publicitaria legal, 
responsable y honesto, que repercutirá en un beneficio para todas las partes implicadas: empresarios, consumidores, competidores y el propio mercado.

Sin embargo, no todo aprovechamiento de la reputación de la marca ajena es sancionable, pues si bien cuando se sobrepasan los límites establecidos los cuales se sustentan principalmente en confundir o engañar al consumidor sobre el origen del producto o servicio, no siempre se produce dicho engaño sino que se utiliza esa estela del competidor para alcanzar un beneficio mayor y acaparar una mayor atención entre el público. 